\title{
PERCEPÇÃO AMBIENTAL DE CRIANÇAS SOBRE PRIMATAS POR MEIO DE MAPAS MENTAIS: SUBSÍDIOS PARA EDUCAÇÃO AMBIENTAL
}

\author{
Emanuel Ubaldino Torres Junior ${ }^{1}$ \\ Mônica Mafra Valença-Montenegro² \\ Carla Soraia Soares de Castro $^{3}$
}

Resumo: A percepção ambiental é essencial no entendimento das relações entre as populações humanas e o ambiente. Neste sentido, buscamos avaliar a percepção ambiental infantil sobre primatas em uma comunidade localizada no entorno da RPPN Engenho Gargaú na Paraíba, Brasil. Foram coletados 102 mapas mentais de crianças e os resultados mostraram que aquelas que tiveram contato anterior com primatas apresentaram maior aproximação com a realidade em seus desenhos, tanto na caracterização destes, quanto do ambiente representado, evidenciando um maior contato com o meio ambiente. Tais resultados subsidiarão futuras pesquisas e programas de Educação Ambiental, especificamente, envolvendo primatas ameaçados de extinção.

Palavras-chave: Etnoecologia; Conservação; Guariba-de-mãos-ruivas; Macaco-prego-galego; Sagui-do-nordeste.

1Universidade Federal da Paraíba, Programa de Pós-Graduação em Ecologia e Monitoramento Ambiental. E-mail: emanuel.torres.junior@gmail.com.br

${ }^{2}$ Centro Nacional de Pesquisa e Conservação de Primatas Brasileiros (CPB; ICMBio). E-mail: monica.montenegro@icmbio.gov.br

3Universidade Federal da Paraíba, Programa de Pós-Graduação em Ecologia e Monitoramento Ambiental. E-mail: csscastro9@gmail.com 


\section{Introdução}

O meio ambiente é percebido e compreendido de forma diferente entre os indivíduos (WOODGATE; REDCLIFT, 1998). Tais diferenças são decorrentes de fatores educacionais ou culturais distintos (HOEFFEL; FADINI, 2007). O conceito de percepção assume que cada indivíduo possui uma imagem do mundo em sua mente (DERDIK, 1989), construída a partir de suas experiências de vida (VESTENA, C.; VESTENA, L., 2003). O uso do mapa mental procura abstrair essa percepção, retratando o ambiente em todos os seus aspectos (GUERREIRO et al., 2005), o qual através do desenho tem sido adotado como estratégia metodológica envolvendo principalmente crianças (BEZERRA; FELICIANO; ALVES, 2008; NETO; DIAS, 2011; REIGADA; TOZONI-REIS, 2004), por ser uma ferramenta de fácil aceitação e prazerosa entre estas, capaz de ser posteriormente decodificado e analisado (ECKERT et al., 2017). A elaboração de desenhos, desta forma, é uma ótima ferramenta para o fornecimento de informações sobre a percepção ambiental e ecológica de determinada comunidade ou grupo (PILLAR, 1996).

É de fundamental importância conhecer como os indivíduos pensam e percebem o ambiente (DIEGUES; ARRUDA, 2001), melhor compreendendo assim a inter-relação entre o homem e o ambiente (MELLAZO, 2005) e, consequentemente, também sua inter-relação com a fauna local. Ao considerar o grupo dos primatas, o Brasil é o país com a maior diversidade de espécies (SIGRIST, 2012), com aproximadamente $20 \%$ dos táxons conhecidos no mundo (CPB/ICMBIO, 2015). Ainda assim, estes primatas estão submetidos a fortes perturbações antrópicas (STRIER, 2007), sendo intensamente afetados pelo desmatamento e fragmentação de seus habitats (MARSH, 2007; CHIARELLO et al., 2008). No que se refere ao bioma Mata Atlântica, embora tenha seu território reduzido a menos de $16 \%$ de sua cobertura original (RIBEIRO et al., 2009), este ainda abriga a maior riqueza de primatas neotropicais endêmicos, reforçando a importância de sua conservação (GONÇALVES; HOEFFEL, 2012). No "Centro de Endemismo Pernambuco", área que correspondente à Mata Atlântica dos estados brasileiros de Alagoas, Pernambuco, Paraíba e Rio Grande do Norte, os remanescentes não chegam a $5 \%$ de sua área original (SILVA; CASTELETI, 2005).

Nesta região, especificamente na Paraíba, podem ser encontradas duas espécies ameaçadas de extinção: guariba-de-mãos-ruivas, Alouatta belzebul Linnaeus 1766, categorizada como vulnerável (BRASIL, 2014); e macacoprego-galego, Sapajus flavius Schreber 1774, em perigo de extinção (BRASIL, 2014). Também são encontradas populações de sagui-do-nordeste, Callithrix jacchus Linnaeus 1758, espécie bastante adaptada a áreas florestais fragmentadas (ANZOLIN BEGOTTI; FREY LANDESMANN, 2008).

A percepção ambiental, ao buscar a compreensão dos indivíduos sobre o ambiente, pode sensibilizar a sociedade sobre a importância da conservação dos recursos naturais (MELLAZO, 2005), inclusive dos primatas. Estudos envolvendo a percepção dos indivíduos contribuem, por exemplo, para o levantamento das deficiências no ensino escolar local e consequente falta de

revista brasileira educação ambiental 
conhecimento ambiental (MALAFAIA; RODRIGUES, 2009). Conhecendo-se estas lacunas, pode-se enfatizar o que deve ser tratado como prioridade em ações de Educação Ambiental (EA) junto às comunidades (MELO; KORF, 2010). Desta maneira, a percepção ambiental infantil tem sido objeto de investigações que visam dar suporte às propostas de EA (ECKERT et al., 2017), proporcionando projetos escolares com uma visão mais crítica e diferenciada do pensamento ideológico que tem dominado a EA tradicional (GUIMARÃES, 2007). Uma EA crítica neste ambiente pode contribuir para que a população local se perceba como sujeito ativo na apropriação e na elaboração do conhecimento, compreendendo que são agentes de mudanças na realidade em que vivem (ZAKRZEVSKI, 2004).

$O$ estudo da percepção ambiental torna-se, assim, fundamental para 0 desenvolvimento e a realização eficaz de uma EA com base local. E a percepção e o conhecimento sobre primatas podem aumentar com a participação da comunidade nestes programas de EA (e. g. BUSS; ROMANOWSKI; BECKER, 2015; COUTO-SANTOS; MOURTHE; MAIABARBOSA, 2004; SICOTTE; UWENGELI, 2002). No entanto, tais estudos no campo de EA ainda são incipientes no Brasil (MARIN, 2008).

Partindo do exposto, considerando a falta de estudos etnoprimatológicos envolvendo crianças, analisou-se a percepção ambiental infantil sobre primatas em uma escola pública no entorno da Reserva Particular do Patrimônio Natural Engenho Gargaú, na Paraíba, Brasil. A hipótese proposta foi de que haveria diferença na percepção de crianças que já avistaram primatas das que nunca avistaram, pois se pressupõe que aquelas que já tiveram contato com os primatas possuem uma percepção ambiental mais realista e detalhada do que as demais.

\section{Material e Métodos}

O estudo foi realizado na comunidade de Lerolândia (658'31.51's, $34^{\circ} 58^{\prime} 55.96^{\prime \prime}$ W), localizada no município de Santa Rita, Paraíba, Brasil. Criada em 1979, a comunidade é reconhecida como um aglomerado rural e ocupa uma área de aproximadamente 10 ha (LIMA; MOREIRA, 2002). Lerolândia situa-se próxima a remanescentes de Mata Atlântica, sendo o principal a Reserva Particular do Patrimônio Natural (RPPN) Engenho Gargaú ( $\left.7^{\circ} 00^{\prime} 43.84^{\prime \prime} \mathrm{S}, 34^{\circ} 57^{\prime} 24.96^{\prime \prime} \mathrm{W}\right)$, localizada aproximadamente a $3 \mathrm{~km}$ da comunidade.

A RPPN Engenho Gargaú, apesar de estar situada em uma área de alta pressão antrópica, circundada por plantações de cana-de-açúcar (Saccharum spp.) (VALENÇA-MONTENEGRO, 2011), compreende um dos maiores fragmentos de Mata Atlântica da Paraíba, com 1058,62 ha (FIALHO; GONÇALVES, 2008). Sabe-se da ocorrência de populações de três espécies de primatas no seu interior: o guariba-de-mãos-ruivas (Alouatta belzebul), o macaco-prego-galego (Sapajus flavius) e o sagui-do-nordeste (Callithrix jacchus) (FIALHO; GONÇALVES, 2008).

Revbea, São Paulo, V. 13, № 2: 294-307, 2018. 
A Escola Municipal de Ensino Fundamental Paulo Jorge Rodrigues de Lima, em Lerolândia, foi selecionada para realização da coleta de dados de percepção utilizando os mapas mentais. A escola, no período de realização do estudo, possuía 635 alunos, distribuídos do primeiro ao quinto ano, segundo informações da direção. Foram inclusos no estudo 102 alunos, do quarto e quinto ano, que assentiram e que tiveram consentimento dos responsáveis para participar da pesquisa. Optou-se trabalhar com tais turmas por se tratar de crianças que já dominavam razoavelmente a escrita, mas que ainda estavam na fase de transição da infância para a adolescência.

Durante cinco campanhas, em abril de 2015 , foi solicitado às crianças que, em uma folha de papel, no formato A4, escrevessem o nome, a idade e se já haviam avistado ao vivo algum primata. Em seguida, foi solicitado que todos desenhassem, de forma livre, os primatas no local que eles costumam avistalos. Para aquelas crianças que nunca avistaram primatas anteriormente, foi pedido que desenhassem o local que haveria primatas de acordo com o seu conhecimento prévio. Foram disponibilizados aos alunos 50 minutos para a prática da atividade, além de lápis de cor, giz de cera e canetas hidrográficas coloridas.

Após a realização dos desenhos, houve uma conversa informal com as crianças, a fim de trocar experiências e conhecer melhor o seu dia a dia e sua relação com a RPPN Engenho Gargaú. Imagens fotográficas das três espécies de primatas que são encontradas na região foram expostas às crianças, garantindo-se desta forma uma maior confiabilidade na troca de informações referentes às espécies de primatas.

Para análise dos mapas mentais, foi utilizada uma abordagem qualiquantitativa (KOZEL; GALVÃO, 2008; PEDRINI; COSTA; GHILARDI, 2010), desconsiderando as habilidades técnicas dos desenhos. Foi investigada se a representação do primata abordava um aspecto: integrado (aquele em que o primata está inserido ao ambiente desenhado), disperso (aquele em que o primata é desenhado à parte dos outros elementos do desenho) ou isolado (aquele em que apenas o primata é desenhado). Em relação ao ambiente representado, seja com o primata integrado ou disperso, o mapa mental foi classificado em: natural (aquele representado por florestas), urbano (representado por zoológicos ou quintais de residências) ou misto (aquele com representação tanto do ambiente natural quanto do urbano). Os mapas mentais apenas com o primata representado em uma árvore, ou em parte dela, foram classificados com uma distribuição do tipo isolada, em virtude da impossibilidade de deduzir em qual tipo de ambiente (natural ou urbano) o primata está inserido.

A fim de apresentar uma percepção mais detalhada, os mapas mentais foram avaliados quanto à presença dos elementos: rios, árvores, frutos, flora, fauna, construções urbanas, estradas, objetos concretos, elementos abstratos (quaisquer elementos de natureza não concreta ou ficcional), além da presença humana. Também foi observado o padrão de coloração dos primatas, considerando: coloração real (aqueles primatas em tonalidade marrom, 
amarela, cinza e/ou preta), coloração abstrata (aqueles primatas em tonalidade verde, azul, vermelha, roxa e/ou rosa) e sem coloração (aqueles desenhados apenas com lápis grafite). O padrão de coloração "real" foi determinado baseado na coloração das espécies de primatas da região (GARBER et al., 2008; OLIVEIRA; LANGGUTH, 2006).

As frequências dos mapas mentais quanto aos aspectos de distribuição, coloração e tipo de ambiente, bem como dos elementos individuais, foram analisadas considerando-se dois grupos: A) das crianças que já avistaram primatas; e B) das crianças que nunca avistaram primatas ao vivo. Para testar a hipótese de que a percepção ambiental difere entre os grupos, comparamos as proporções dos mapas mentais através do teste $Z$ para os aspectos de distribuição, coloração, ambiente e elementos. O nível de significância adotado foi de 5\%.

\section{Resultados}

Dos 102 mapas mentais coletados, um por criança (grupo $A$ : $n=74$; grupo $B: n=28), 51 \%$ foram de meninas e $49 \%$ de meninos, com uma idade média de 10 anos para toda amostra ( $\sigma=1.4$ anos). Todas as crianças residem na comunidade e $92 \%$ são naturais do local. Entre os aspectos analisados, apenas o padrão de coloração (Figura 1), real e abstrato, dos primatas apresentou diferença significativa para o grupo $A(Z=3.8 ; p<0.00)$ e grupo $B$ $(Z=-5.61 ; p<0.00)$. No grupo das crianças que já havia tido contato visual com primatas, grupo $\mathrm{A}$, houve a predominância da coloração real (83.8\%), e no grupo daquelas que nunca viram primatas, grupo $\mathrm{B}$, predominou a coloração abstrata (42.9\%).

Em ambos os grupos, foi observada uma predominância integrada dos primatas $(A=47.3 \%$; $B=57.1 \%)$ (Figura 2$)$, bem como maior representação do ambiente natural $(A=73.3 \% ; B=66.7 \%)$ e de zoológicos no ambiente urbano $(A=19.6 \% ; B=9.5 \%)$ (Figura 3$)$. A representação de quintais foi observada apenas no grupo B (4.8\%). A respeito dos elementos representados individualmente, houve diferença significativa entre os grupos apenas para a classe de elementos de natureza abstrata $(Z=-2.70 ; p=0.007)$. A presença humana foi observada apenas nos mapas mentais do grupo $A(4 \%)$, havendo alusão à caça e ao desmatamento. Para ambos os grupos, houve predomínio de elementos naturais, como árvores, frutos e flora no geral (Figura 4).

Quanto aos tipos de frutos representados, seja em árvores ou dispersos no desenho, ambos os grupos registraram a presença de banana $(20.6 \%)$, maçã $(14.7 \%)$ e coco (6\%). Em relação à fauna, além dos primatas, o grupo $\mathrm{A}$ também representou peixes $(6.7 \%)$ e pássaros $(4 \%)$, enquanto o grupo $B$, apenas pássaros (3.4\%). Os objetos representados pelo grupo $A$ foram compostos principalmente por itens encontrados em zoológicos, como jaulas e placas (63.6\% dos objetos) e, pelo grupo B, em quintais, como vasos de flores e balanços (71.4\% dos objetos). 

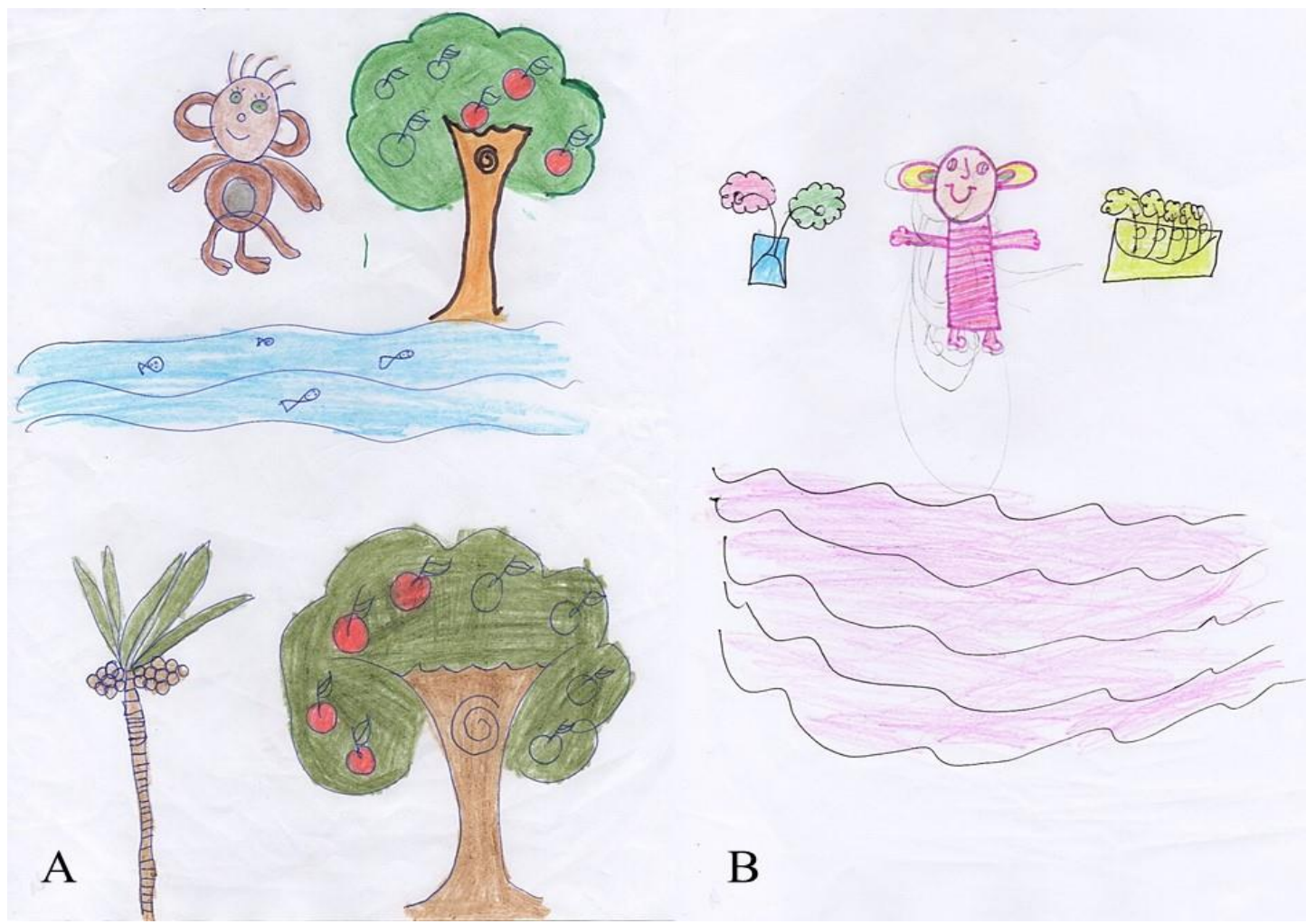

Figura 1: Padrão de coloração em mapa mental de criança que já avistou primata anteriormente (A) e por criança que nunca avistou (B). Fonte: Autoria própria.

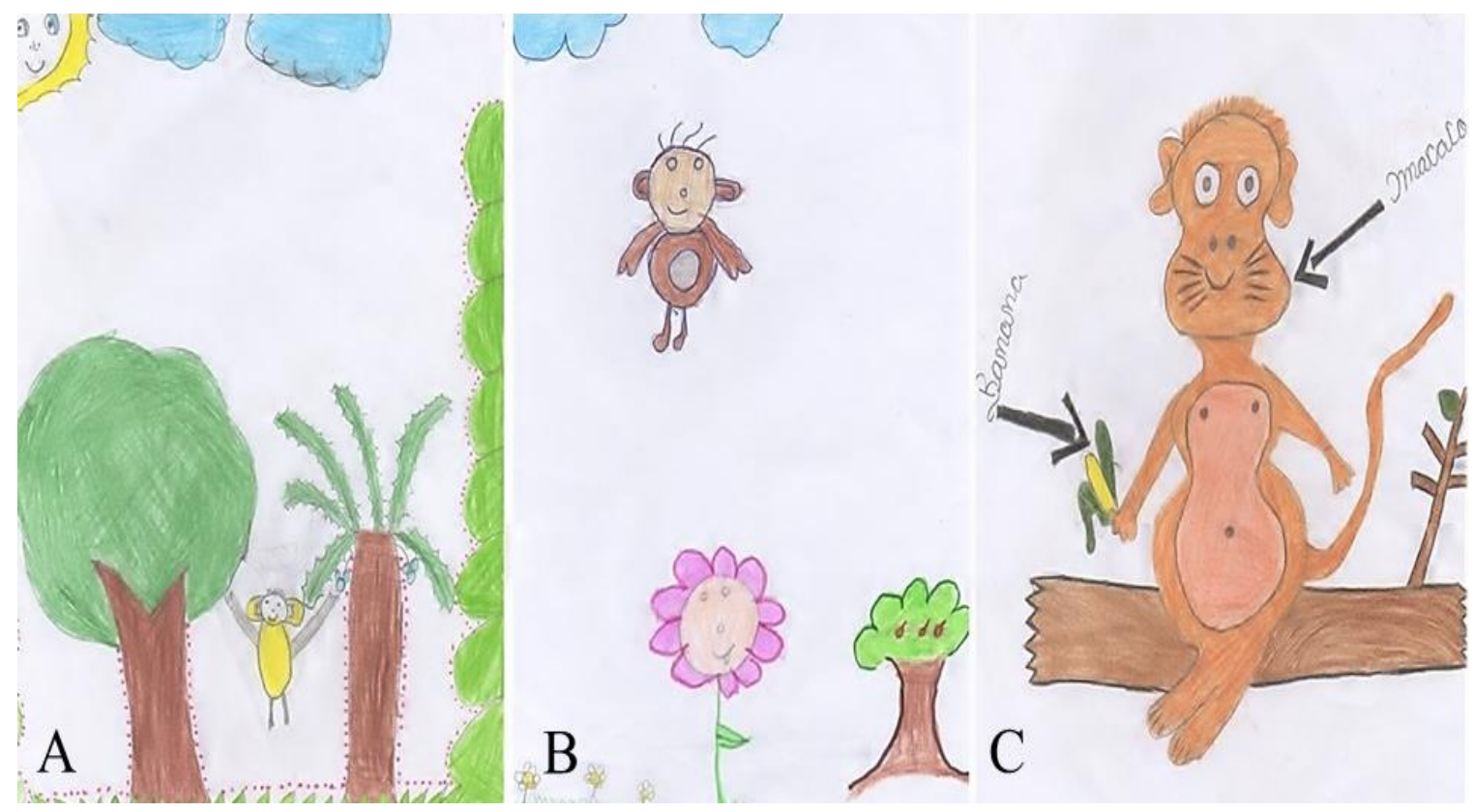

Figura 2: Mapa mental com distribuição integrada $(A)$, dispersa $(B)$ e isolada $(C)$, relativa à posição do primata no desenho. Fonte: Autoria própria. 


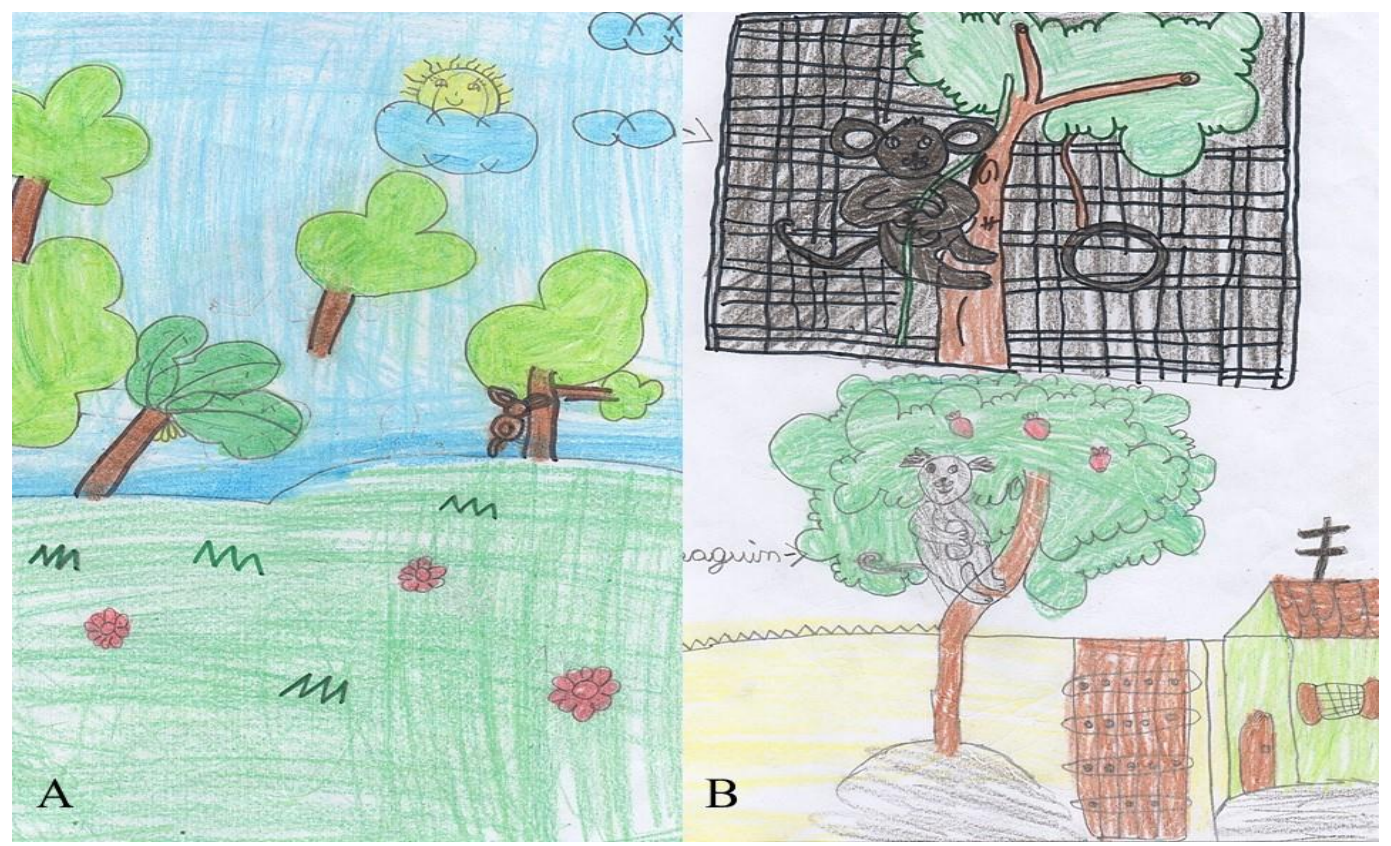

Figura 3: Mapa mental com representação do ambiente natural (A) e urbano (B).

\section{Fonte: Autoria própria.}

100

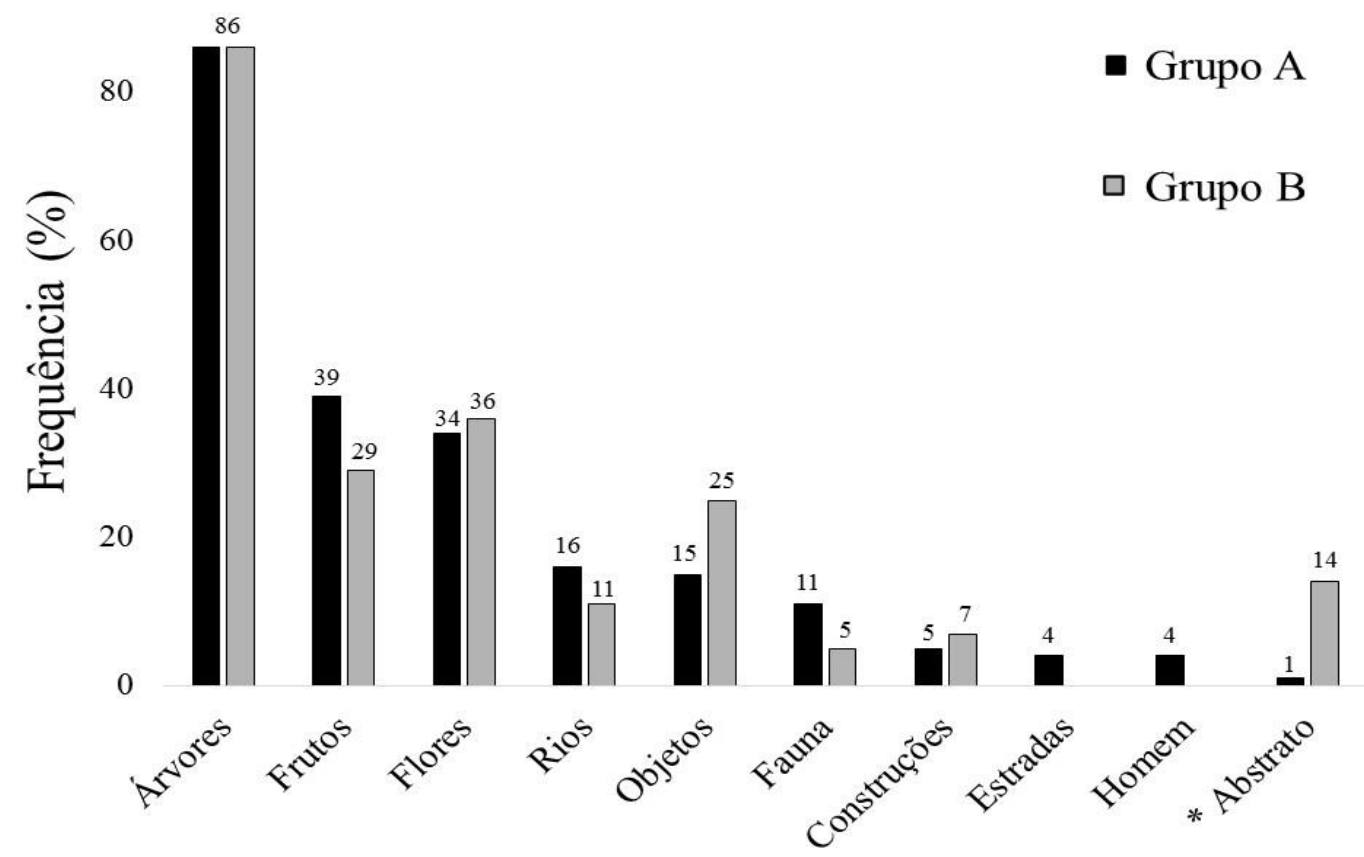

Figura 4: Frequência dos mapas mentais por classe de elementos para o grupo de crianças que já avistaram primatas (A); e para o grupo das que nunca avistaram primatas (B). $\left(^{*}\right)$ Indica diferença significativa entre os grupos. Fonte: Autoria própria. 


\section{Discussão}

A empatia por animais é uma das manifestações mais evidentes da biofilia, a qual explica que os seres humanos têm uma ligação emocional inata com a natureza (WILSON, 1993). As crianças apresentam uma maior afinidade com os animais que elas têm maior contato, seja devido ao convívio físico, ou por meio da mídia (MARQUES, 1995). Os primatas, além de serem considerados animais carismáticos, possuem grande apelo popular, especialmente por suas características sociais e forte semelhança com a espécie humana (COUTO-SANTOS; MOURTHÉ; MAIA-BARBOSA, 2008).

Os resultados encontrados em Lerolândia evidenciam que as crianças que já tiveram contato com primatas possuem uma percepção ambiental mais realista que as demais, apresentando desenhos de primatas com uma coloração compatível com a realidade, além de não fazerem uso de elementos abstratos em seus desenhos. Possivelmente, essas crianças apresentam algum tipo de interação com a RPPN Engenho Gargaú, visto que o Rio Vermelho, que se encontra no interior da RPPN, é visitado frequentemente pela comunidade como opção de lazer, inclusive pelas crianças.

Percebe-se que a maioria das crianças compreendem os primatas através de uma visão naturalista, representando aspectos abióticos e bióticos do habitat natural dos primatas. Quanto mais próximas as crianças estão de ambientes naturais, como Unidades de Conservação, maior é a percepção das mesmas sobre a biota local (REMPEL et al., 2008). Pois estas crianças apresentam maiores oportunidades para interagir com os elementos e processos naturais que ocorrem no local, conhecendo-os tanto por experiência própria como por meio do conhecimento que lhes é transmitido, descrevendo assim mais facilmente o ambiente em seu entorno (PROFICE et al., 2015). Eckert et al. (2017), observaram que a percepção ambiental de estudantes no entorno da Reserva Biológica de Santa Isabel, em Sergipe, indicou conhecimento das problemáticas ambientais locais, além de indícios de afeição pelo ambiente no qual estão inseridos. Um contato mais próximo com estes ambientes naturais, portanto, pode contribuir para uma melhor percepção e detalhamento em mapas mentais (GOLDBERG; YUNES; FREITAS, 2005). Segundo as crianças, pode-se observar o sagui e o macaco-prego-galego nas proximidades do Rio Vermelho, facilitando assim o encontro com estes primatas.

Por outro lado, o contato com primatas também pode ter ocorrido em ambiente não natural. Devido a sua alta plasticidade, o sagui comumente é encontrado em ambientes urbanos, como praças e quintais de residências, caso haja oferta de alimento (SILVA, G.; VERÍSSIMO; OLIVEIRA, 2011). Além disso, em 2014, a escola realizou uma visita ao Parque Zoobotânico Arruda Câmara, localizado na cidade de João Pessoa, aonde foram observadas diversas espécies de primatas, inclusive o macaco-prego-galego, em cativeiro. Esta é a provável razão do destaque que foi dado aos zoológicos dentre os ambientes urbanos representados nos mapas mentais.

revista brasileira educação ambiental 
Quanto aos demais representantes da fauna, também identificados nos mapas, existe uma consistência com outros trabalhos de percepção ambiental, apresentando uma predominância de pássaros (e. g. BOER, 1994; ELORANTA; YLI-PANULA, 2005; PEDRINI; COSTA; GHILARDI, 2010; PROFICE et al., 2015; SCHWARZ; SEVEGNANI; ANDRÉ, 2007). Animais que voam e cantam são mais fáceis de serem avistados no ambiente (PEDRINI; COSTA; GHILARDI, 2010), além de serem animais que não exigem muita habilidade técnica para serem desenhados, facilitando sua representação em mapas mentais (PROFICE et al., 2015). Quanto à presença de peixes, o Rio Vermelho e outros corpos d'águas presentes na região podem ter contribuído para uma maior percepção destes animais pelas crianças, dentre a fauna silvestre local. A representação destes integrantes da fauna indica uma boa percepção do ambiente natural por parte das crianças. $O$ baixo número de desenhos apresentando demais animais é aceitável em virtude de não ter sido explicitamente solicitado outros animais, além dos primatas, durante a realização da atividade.

Em relação aos frutos contidos nos desenhos, a banana e a maçã foram os itens mais representados pelas crianças no geral. Apesar de também não ter sido solicitada a representação de componentes da dieta dos primatas, há uma associação cultural intrínseca entre primatas e frutos, principalmente em relação à banana (BRASILEIRO; ALMEIDA; SAITO, 2011), mesmo sendo um fruto exótico e não integrante da dieta de primatas brasileiros em seu habitat natural. Devido a este hábito cultural e possível familiaridade, acredita-se que a representação destes frutos seja mais cômoda para as crianças (BEZERRA; FELICIANO; ALVES, 2008).

Uma baixa representação humana em mapas mentais já foi relatada anteriormente entre crianças (e. g. PROFICE et al., 2015; SCHWARZ; SEVEGNANI; ANDRÉ, 2007), evidenciando que estas se colocam apenas como observadoras do ambiente, não se sentindo integradas a ele (BRESOLIN; ZAKRZEVSKI; MARINHO, 2010; PEDRINI; COSTA; GHILARDI, 2010). Barreto e Cunha (2016), através da aplicação de questionários em escolas no Recôncavo Baiano, observaram uma tendência nas crianças em excluir elementos culturais e humanos acerca do termo "meio ambiente". Ainda assim, pôde-se observar nos mapas mentais em Lerolândia evidências de caça e desmatamento. Crianças também são capazes de identificar problemas ambientais (GODOY et al., 2008), conforme observado por Eckert et al. (2017), e embora exista fiscalização ainda há na RPPN Engenho Gargaú ocorrência de caça e apanha, inclusive de primatas, bem como corte de espécies arbóreas (VALENÇA-MONTENEGRO, 2011).

Como geralmente são registrados nos mapas mentais apenas os elementos de maior importância, ou aqueles relacionados aos aspectos do cotidiano dos indivíduos (BRESOLIN; ZAKRZEVSKI; MARINHO, 2010; ROCHA, 2007), pode-se inferir que as crianças que nunca avistaram primatas, ao priorizarem representar objetos encontrados em quintais, apresentam uma familiaridade maior com o ambiente domiciliar e um menor contato com a 
RPPN e com outras áreas naturais. É possível que parte dessas crianças, que nunca avistaram primatas, ainda não saiba indicar corretamente 0 habitat natural destes, mesmo estando próximas a uma área de proteção ambiental.

Em estudo realizado por Buss, Romanowski e Becker (2015), no Parque Estadual de Itapuã, no Rio Grande do Sul, foi demonstrado que a comunidade tinha uma visão muito positiva do bugio-ruivo (Alouatta guariba clamitans Cabrera, 1940), provavelmente como consequência de atividades de EA desenvolvidas durante 0 processo de implantação do Parque. Nesta perspectiva, cabe à escola, como espaço formal de ensino, a prática de atividades de EA de forma contínua, desenvolvendo nas crianças novos saberes e valores ambientais (CURADO; ANGELINI, 2006; OLIVEIRA, 2006). Sobretudo quando está privilegiadamente localizada próxima a uma área de proteção ambiental, como a RPPN Engenho Gargaú, pois estas atividades educacionais, quando ocorrem ao ar livre, ajudam a promover a conservação do ambiente como um todo (BOGNER; WISEMAN, 2004).

\section{Conclusões}

A hipótese de que a percepção sobre primatas difere segundo o contato com os mesmos foi confirmada, pois os mapas mentais daquelas crianças que já tiveram contato mostraram maior riqueza de detalhes e melhor aproximação com a realidade, especialmente em relação a caracterização dos primatas e ambiente. As crianças que nunca avistaram primatas aparentemente desenharam por diversão, colorindo e se expressando principalmente de forma abstrata. Esta percepção pouco realista reforça a necessidade de atividades de EA junto à comunidade escolar, incentivando o contato das crianças com 0 ambiente natural, ainda mais sendo uma escola rural, necessitando de uma EA adaptada para os problemas ambientais locais.

Desta forma, recomendamos um programa de EA envolvendo a comunidade escolar e a RPPN Engenho Gargaú, a fim de proporcionar esclarecimentos e informações sobre as espécies de primatas ali presentes, principalmente em relação ao guariba-de-mãos-ruivas e ao macaco-pregogalego, que estão ameaçados de extinção, bem como apontar e discutir alguns dos principais problemas ambientais que são encontrados na região, como a caça e o desmatamento ilegal.

\section{Agradecimentos}

Nós agradecemos à coordenação e aos alunos da Escola Paulo Jorge Rodrigues de Lima pelo apoio e participação; à Coordenação de Aperfeiçoamento de Pessoal de Nível Superior (CAPES), pelo apoio financeiro. Essa pesquisa teve a aprovação do Comitê de Ética da Universidade Federal da Paraíba (no. 0651/14). 


\section{Referências}

ANZOLIN BEGOTTI, R.; FREY LANDESMANN, L. Predação de ninhos por um grupo híbrido de saguis (Callithrix jacchus/penicillata) introduzidos em área urbana: implicações para a estrutura da comunidade. Neotropical Primates, v. 15, n. 1, p. 28-29, 2008.

BARRETO, L.M.; CUNHA, J.S. Concepções de meio ambiente e Educação Ambiental por alunos do ensino fundamental em Cruz das Almas (BA): um estudo de caso. Revista Brasileira de Educação Ambiental, v. 11, n. 1, p. 315-326, 2016.

BEZERRA, T.M.O.; FELICIANO, A.L.P.; ALVES, A.G.C. Percepção ambiental de alunos e professores do entorno da Estação Ecológica de Caetés-Região Metropolitana do Recife-PE. Biotemas, v. 21, n. 1, p. 147-160, 2008.

BOER, N. Meio ambiente na percepção de alunos que recebem educação ambiental na escola. Ciência e Ambiente, Porto Alegre, v.1, n.8, p.91-101, 1994.

BOGNER, F.X.; WISEMAN, M. Outdoor ecology education and pupils' environmental perception in preservation and utilization. Science Education International, v. 15, n. 1, p. 27-48, 2004.

BRASIL. Portaria o 444, de 17 de dezembro de 2014. Reconhece as espécies da fauna brasileira ameaçadas de extinção. Diário Oficial [da] República Federativa do Brasil, Brasília, v. 245, p. 121-126, 2014.

BRASILEIRO, L.; ALMEIDA, L.E.; SAITO, C.H. Percepção dos visitantes do Parque Nacional de Brasília sobre sua interação com Cebus libidinosus: subsídios para uma prática de Educação Ambiental e de conduta consciente de visitantes de Unidade de Conservação da Natureza. Revista Eletrônica do Mestrado de Educação Ambiental, v. 26, p. 141-153, 2013.

BRESOLIN, A.J.; ZAKRZEVSKI, S.B.B.; MARINHO, J.R. Percepção, comunicação e educação ambiental em unidades de conservação: um estudo no Parque Estadual de Espigão Alto-Barracão/RS-Brasil. Revista Perspectiva, v. 34, n. 128, p. 103-114, 2010.

BUSS, G.; ROMANOWSKI, H.P.; BECKER, F.G. O bugio que habita a mata e a mente dos moradores de Itapuã-Uma análise de percepção ambiental no entorno do Parque Estadual de Itapuã, Viamão, RS. Revista Biociências, v. 21, n. 2, p. 14-28, 2015.

CHIARELLO, A.G.; et al. Mamíferos ameaçados de extinção no Brasil. In: MACHADO, A.B.M.; DRUMMOND, G.M.; PAGLIA, A.P. (Eds.). Livro Vermelho da Fauna Brasileira Ameaçada de Extinção. Brasília: Fundação Biodiversitas, 2008. p. 681-880.

COUTO-SANTOS, F.R.; MOURTHÉ, I.M.C.; MAIA-BARBOSA, P.M. Levantamento preliminar da concepção de jovens estudantes sobre a conservação de primatas da Mata Atlântica em duas instituições não-formais de ensino. Ensaio Pesquisa em Educação em Ciências, v. 6, n. 2, p. 1-11, 2004.

Revbea, São Paulo, V. 13, № 2: 294-307, 2018. 
CPB/ICMBIO. Centro Nacional de Pesquisa e Conservação de Primatas Brasileiros. Primatas Brasileiros. 2015. Disponível em: <http://www.icmbio. gov.br/cpb/primatas-brasileiros.html>. Acesso em: 27 abr. 2015.

CURADO, P.M.; ANGELINI, R. Avaliação de atividade de Educação Ambiental em trilha interpretativa, dois a três anos após sua realização. Acta Scientiarum Biological Sciences, v. 28, n. 4, p. 395-401, 2006.

DERDYK, E. Formas de pensar o desenho: desenvolvimento do grafismo infantil. São Paulo: Scipione, 1989. 239 p.

DIEGUES, A.C.; ARRUDA, R. Saberes tradicionais e biodiversidade no Brasil. São Paulo: USP/NUPAUB, 2001. 211 p.

ECKERT, N.O.S.; et al. Percepção ambiental de estudantes da zona rural sobre a Reserva Biológica de Santa Isabel, Pirambu (SE). Revista Brasileira de Educação Ambiental, v. 12, n. 1, p. 43-57, 2017.

ELORANTA, V.; YLI-PANULA, E. Animals in the landscape drawings of Finnish and Russian young people in the landscape they want to conserve. Nordic Studies in Science Education, v. 1, n. 2, p. 5-17, 2012.

FIALHO, M.S.; GONÇALVES, G.F. Primates Da RPPN Gargaú, Paraíba, Brasil. Neotropical Primates, v. 15, n. 2, p. 50-54, 2008.

GARBER, P.A.; et al. (Ed.). South American primates: comparative perspectives in the study of behavior, ecology, and conservation. Springer Science \& Business Media, 2008. 568 p.

GODOY, R.; et al. Of trade and cognition: markets and the loss of folk knowledge among the Tawahka Indians of the Honduran rain forest. Journal of Anthropological Research, v.54, v.2, p.219-234, 1998.

GOLDBERG, L.G.; YUNES, M.A.M.; FREITAS, J.V. O desenho infantil na ótica da ecologia do desenvolvimento humano. Psicologia em Estudo, v. 10, n. 1, p. 97-106, 2005.

GONÇALVES, N.M.; HOEFFEL, J.L.M. Percepção ambiental sobre Unidades de Conservação: os conflitos em torno do Parque Estadual de Itapetinga - SP. Revista VITAS, n. 3, p. 1-15, 2012.

GUERREIRO, O.; et al. Definição de uma metodologia para modelagem de agentes inteligentes difusos a partir da técnica de mapas mentais: Um estudo de caso baseado na percepção e comportamento de usuários da praia Brava, SC-Brasil. OLAM, v. 5, n. 1, p. 73-87, 2005.

GUIMARAES, M. Caminhos da Educação Ambiental: da forma à ação. Campinas: Papirus, 2007.112 p.

HOEFFEL, J.L.; FADINI, A.A.B. Percepção Ambiental. In: FERRARO JÚNIOR, L. A. (Org.). Encontros e caminhos. Brasília: MMA, p. 255-262, 2007.

KOZEL, S.; GALVÃO, W. Representação e Ensino de Geografia: contribuições teórico-metodológicas. Ateliê Geográfico, v. 2, n. 3, p. 33-48, 2008.

revista brasileira educação ambiental 
LIMA, E.R.V.; MOREIRA, E. Expansão canavieira e transformações no espaço agrário do município de Santa Rita: o caso do núcleo de urbanização rural de Lerolândia. Cadernos do Logepa: Série Monografia, v. 1, p. 2-34, 2002.

MALAFAIA, G.; LIMA RODRIGUES, A.S. Percepção ambiental de jovens e adultos de uma escola municipal de ensino fundamental. Revista Brasileira de Biociências, v. 7, n. 3, p. 266-274, 2009.

MARIN, A.A. Pesquisa em educação ambiental e percepção ambiental. Pesquisa em Educação Ambiental, v. 3, n. 1, p. 203-222, 2008.

MARQUES, J.G W. Pescando pescadores: etnoecologia abrangente no baixo São Francisco alagoano. São Paulo: NUPAUB-USP, 1995. 285 p.

MARSH, L.K. The nature of fragmentation. In: Primates in Fragments: Ecology and Conservation. MARSH, L.K. (Ed.). New York: Kluwer Academic/Plenum Publishers, 2003.

MELAZO, G.C. A percepção ambiental e educação ambiental: uma reflexão sobre as relações interpessoais e ambientais no espaço urbano. Olhares \& Trilhas, v. 6, n. 6, p. 45-51, 2009.

MELO, E.F.R.Q.; KORF, E.P. Percepção e sensibilização ambiental de universitários sobre os impactos ambientais da disposição de resíduos sólidos urbanos em Passo Fundo-RS. Revista Brasileira de Educação Ambiental, v. 5, n. 1, p. 45-54, 2010.

NETO, F.O.L.; DIAS, R.H.L. Mapas mentais e construção do ensino de Geografia significativo: Algumas reflexões. Revista Geoaraguaia, v. 1, n. 1, 2011.

OLIVEIRA, M.M.; LANGGUTH, A. Rediscovery of Marcgrave's Capuchin Monkey and Designation of a Neotype for Simia flavia Schreber, 1774 (Primates, Cebidae). Boletim do Museu Nacional, n. 523, p. 1-16, 2006.

OLIVEIRA, N.A.S. A educação ambiental e a percepção fenomenológica, através de mapas mentais. Revista Eletrônica do Mestrado de Educação Ambiental, v. 16, p. 32-46, 2012.

PEDRINI, A.; COSTA, E.A.; GHILARDI, N. Percepção Ambiental de crianças e pré-adolescentes em vulnerabilidade social para projetos de Educação Ambiental. Ciência \& Educação, v. 16, n. 1, p. 163-179, 2010.

PILLAR, A.D. Desenho e construção de conhecimento na criança. Porto Alegre: Artes Médicas, 1996. 255 p.

PROFICE, C.; et al. Children's environmental perception of protected areas in the Atlantic Rainforest. Psyecology, v. 6, n. 3, p. 328-358, 2015.

REIGADA, C.; TOZONI-REIS, M. F. C. Educação ambiental para crianças no ambiente urbano: uma proposta de Pesquisa-Ação. Ciência \& Educação, v. 10, n. 2, p. 149-159, 2004.

REMPEL, C.; et al. Percepção Ambiental da Comunidade Escolar Municipal sobre a Floresta Nacional de Canela, RS. Revista Brasileira de Biociências, v. 6 , n. 2, p. 141-147, 2008.

Revbea, São Paulo, V. 13, № 2: 294-307, 2018. 
RIBEIRO, M.C.; METZGER, J.P.; MARTENSEN, A.C.; PONZONI, F.J.; HIROTA, M.M. The Brazilian Atlantic Forest: How much is left, and how is the remaining forest distributed? Implication for conservation. Biological Conservation, v. 142, n. 6, p. 1141-1153, 2009.

ROCHA, L.B. Mapa mental: Forma de comunicação espacial. In: TRINDADE, G. A.; CHIAPETTI, R.J.N. (Orgs.). Discutindo Geografia: Doze razões para se (re)pensar a formação do professor. Ilhéus: Editus, 2007. p. 159-175.

SCHWARZ, M.L.; SEVEGNANI, L.; ANDRÉ, P. Representações da mata atlântica e de sua biodiversidade por meio dos desenhos infantis. Ciência \& Educação, v. 13, n. 3, p. 369-388, 2007.

SICOTTE, P.; UWENGELI, P. Reflections on the concept of nature and gorillas in Rwanda: implications for conservation. In: FUENTES, A.; WOLFE, L. (Eds.). Primates face to face: the conservation implications of human-nonhuman primate interconnections. New York: Cambridge University Press, 2002. p. 163-181.

SIGRIST, T. Mamíferos do Brasil: Uma Visão Artística. Vinhedo: Avis Brasilis Editora, 2012. 450 p.

SILVA, G.M.M.; VERÍSSIMO, K.C.S.; OLIVEIRA, M.A.B. Orçamento das atividades diárias de dois grupos de Callithrix jacchus em área urbana. Revista de Etologia, v. 10, n. 2, p. 57-63, 2011.

SILVA, J.M.C.; CASTELETI, C.H. Estado da biodiversidade da Mata Atlântica brasileira. In: GALINDO-LEAL, C.; CÂMARA, I. G. (Eds.). Mata Atlântica: Biodiversidade, Ameaças e Perspectivas. Belo Horizonte: SOS Mata Atlântica, 2005. p. 43-59.

STRIER, K. What New World primates contribute to primatology. A Primatologia no Brasil, v. 10, p. 1-16, 2007.

VALENÇA-MONTENEGRO, M.M. Ecologia de Cebus flavius (Schreber, 1774) em remanescentes de Mata Atlântica no Estado da Paraíba. 2011. 131f. Tese (Doutorado em Ecologia) - Escola Superior de Agricultura Luiz de Queiroz, Universidade de São Paulo, São Paulo, 2011.

VESTENA, C.L.B.; VESTENA, L.R. Percepção e educação ambiental no ensino fundamental das séries iniciais do sudoeste paranaense. Analecta, v. 4, n. 1, p. 103-114, 2003.

WILSON, E.O. Biophilia and the Conservation Ethic. In: KELLERT, S.; WILSON, E.O. (Orgs.). The Biophilia Hypothesis. Washington: Island, 1993. p. 31-41.

WOODGATE, G.; REDCLIFT, M. From a 'sociology of nature' to environmental sociology: beyond social construction. Environmental Values, v. 7, n. 1, p. 324, 1998.

ZAKRZEVSKI, S.B. Por uma educação ambiental crítica e emancipatória no meio rural. Revista Brasileira de Educação Ambiental, v. 1, p. 79-86, 2004.

revista brasileira educação ambiental 